\title{
Lipid Turnover in Oleaginous Yeasts
}

\author{
By JANE E. HOLDSWORTH AND COLIN RATLEDGE* \\ Department of Biochemistry, University of Hull, Hull HU6 $7 R X, U K$
}

(Received 17 August 1987; revised 16 October 1987)

\begin{abstract}
When eight strains of the oleaginous yeasts Candida curvata, Lipomyces starkeyi, Rhodosporidium toruloides and Trichosporon cutaneum were starved of carbon after having accumulated lipid up to $34 \%$ of their biomass, the lipid was readily converted to new biomass in all cases except the two strains of L. starkeyi. When C. curvata $\mathrm{D}$ was grown in a two-stage chemostat with the second stage as a carbon-starvation vessel (but containing $\mathrm{NH}_{4}^{+}$) biosynthesis of new biomass reached $1.9 \pm 0.2 \mathrm{~g}$ per g lipid utilized. Experiments in a single-stage chemostat undergoing transition from lipid accumulation (nitrogen-limited medium) to carbon-starvation conditions showed that the lipid in $C$. curvata was rapidly mobilized. When the lipid was pre-labelled with ${ }^{14} \mathrm{C}$, a transitory pool of rapidly metabolizable non-lipid material appeared within $1.5 \mathrm{~h}$ of the initiation of starvation. Rates of lipid loss indicated that initiation of lipid degradation occurred immediately carbon was lost from the external medium.
\end{abstract}

\section{INTRODUCTION}

The accumulation of lipid in micro-organisms has been well described from both biotechnical and biochemical viewpoints (Ratledge \& Boulton, 1985; Ratledge, 1986). The major lipid which is stored, usually in the form of discrete droplets, is triacylglycerol; it can account for up to $80 \%$ of the biomass in certain oleaginous organisms. The accumulation of lipid depends upon there being a surfeit of carbon and a deficit of some other nutrient, usually nitrogen, in the growth medium. It has been presumed that lipid would act as a storage material to be used by the cells, akin to other energy reserves (Dawes, 1985), if they subsequently enter a period of starvation. However, unequivocal evidence for utilization of lipid reserves in starved yeasts has not been presented (see Dawes \& Senior, 1973) though Deinema (1961) found several oleaginous yeasts that gradually lost their lipid when starved, and whose viability sharply decreased once the lipid had been consumed.

As this laboratory has an interest in the accumulated lipids of eukaryotic micro-organisms, we have sought to resolve the question of lipid utilization as an endogenous energy and carbon reserve in a number of oleaginous yeasts. Three complementary approaches have been used in case it was argued that lipolysis could be triggered by some unsuspected insult to the cells. If similar conclusions could be drawn from the three separate approaches, we would then feel confident of our interpretations of the data.

\section{METHODS}

Yeasts. Yeasts were obtained from culture collections as designated (CBS, Centraalbureau voor Schimmelcultures, Delft, Netherlands; NCYC, National Collection of Yeast Cultures, Norwich, UK; ATCC, American Type Culture Collection, Rockville, Md., USA). Candida curvata D (= Apiotrichum curvatum ATCC 20599), C. curvata $\mathbf{R}$ and Trichosporon cutaneum $\mathbf{4 0}$ were kindly supplied by Professor E. G. Hammond, Iowa State University, Ames, Iowa, USA.

Media. The basal media for batch and continuous culture experiments contained the following constituents ( $\mathrm{g} \mathrm{l}^{-1}$ ): $\mathrm{KH}_{2} \mathrm{PO}_{4}, 7 \cdot 0 ; \mathrm{Na}_{2} \mathrm{HPO}_{4}, 2 \cdot 0 ; \mathrm{MgSO}_{4} .7 \mathrm{H}_{2} \mathrm{O}, 1 \cdot 5$; yeast extract (Oxoid), $1.5 ; \mathrm{CaCl}_{2} .2 \mathrm{H}_{2} \mathrm{O}, 0 \cdot 1$; $\mathrm{FeCl}_{3} .6 \mathrm{H}_{2} \mathrm{O}, 0.008 ; \mathrm{ZnSO}_{4} .7 \mathrm{H}_{2} \mathrm{O}, 0.001 ; \mathrm{CuSO}_{4} .5 \mathrm{H}_{2} \mathrm{O}, 0.0001 ; \mathrm{Co}\left(\mathrm{NO}_{3}\right)_{2} .6 \mathrm{H}_{2} \mathrm{O}, 0.0001 ; \mathrm{MnSO}_{4} .5 \mathrm{H}_{2} \mathrm{O}$, 
0.0001 , with, for balanced media, $\mathrm{NH}_{4} \mathrm{Cl}$ at $3 \mathrm{gl}^{-1}$ and glucose at $30 \mathrm{gl}^{-1}$; for nitrogen-limited media $\mathrm{NH}_{4} \mathrm{Cl}$ at 0.5 $\mathrm{g} \mathrm{I}^{-1}$ and carbon source at $30 \mathrm{~g} \mathrm{I}^{-1}$; for carbon-starvation media $\mathrm{NH}_{4} \mathrm{Cl}$ at $3 \mathrm{~g} \mathrm{I}^{-1}$ and no carbon source. The $\mathrm{pH}$ in all media was adjusted to $\mathrm{pH} 5.5$ prior to the addition of carbon source and micronutrients.

Batch culture medium was sterilized in situ by autoclaving at $121^{\circ} \mathrm{C}$ for $15 \mathrm{~min}$. Medium for continuous culture experiments was sterilized by membrane filtration (pore size $0.2 \mu \mathrm{m}$ ), collected in sterile 201 aspirators and kept for $3 \mathrm{~d}$ at room temperature to ensure sterility before use.

Growth of yeasts. Batch culture experiments. Oleaginous yeasts were cultivated in 11 vortex-aerated bottles containing $700 \mathrm{ml}$ of medium at $30^{\circ} \mathrm{C}$. After $5 \mathrm{~d}$, two duplicate samples $(20 \mathrm{ml})$ were taken to determine biomass concentration and lipid content and then immediately approximately $200 \mathrm{ml}$ of the culture was quickly but aseptically transferred to a similar vessel containing $400 \mathrm{ml}$ of carbon-starvation medium already at $30^{\circ} \mathrm{C}$. A further $20 \mathrm{ml}$ sample was taken in duplicate immediately after transfer to calculate the new biomass concentration and thus the volume of culture transferred. Initial glucose and $\mathrm{NH}_{4}^{+}$concentrations were also determined by analysis of the supernatants. Yeasts were grown in the second vessel for a further $36 \mathrm{~h}$ prior to determining biomass, lipid content, residual glucose and $\mathrm{NH}_{4}^{+}$concentration.

Two-stage continuous culture experiments.

C. curvata $\mathrm{D}$ was grown in a two-stage continuous culture with the first vessel being a 1.51 chemostat with an operating volume of 1.251 . The second vessel was a similar unit with a working volume of 3.751 . The vessels were connected in such a way that the entire output of vessel 1 was pumped directly into vessel 2 . The hold-up time of the yeast in the connecting tube was about $50 \mathrm{~s}$. Fresh, carbon-free medium was also pumped into vessel 2 . The yeast was grown at $30^{\circ} \mathrm{C}$ and the cultures in both vessels were maintained at $\mathrm{pH} 5.5$ by automatic addition of $\mathrm{KOH}$. Foaming was controlled by the timed addition of antifoam (polyglycol P2000; Bevaloid Ltd, Beverley, UK).

Steady-state conditions in vessel 1 were unchanged during the entire course of the experiment. After a change in the steady-state conditions in vessel 2 , at least five changes of medium occurred before samples were taken on two successive days. If the biomass values did not agree, further samples were taken until they did. The dilution rate in vessel 2 was varied by altering the flow rate of carbon-free medium into stage 2 . The concentration of glucose in stage 2 remained at about $0.025 \mathrm{~g} \mathrm{l}^{-1}$ and that leaving stage 1 was at a steady-state concentration of $2 \mathrm{~g} \mathrm{l}^{-1}$.

The increase in biomass (or decrease in lipid) per litre of medium in vessel 2 was calculated as

$$
x^{\prime}-x f \mid f^{\prime}
$$

where $x$ and $x^{\prime}$ are the biomass (or lipid) concentrations $\left(\mathrm{g}^{-1}\right)$ entering and leaving vessel 2 at flow rates $f$ and $f^{\prime}$ $\left(1 \mathrm{~h}^{-1}\right)$ respectively. The specific growth rate of the yeast in the second stage was calculated as

$$
\mu^{\prime}=\frac{f^{\prime} x^{\prime}-f x}{v_{2} x^{\prime}}
$$

where $v_{2}$ is the volume of medium in vessel 2 .

Single-stage chemostat transition studies. C. curvata $\mathrm{D}$ was grown at $30^{\circ} \mathrm{C}$ on nitrogen-limited media in a chemostat, working volume $1.25 \mathrm{l}$, at a dilution rate of $0.05 \mathrm{~h}^{-1}$ with the $\mathrm{pH}$ and foaming controlled as given above for the operation of the two-stage chemostat. When at steady state, the incoming media was switched from nitrogen-limited to carbon-starvation (see above) to give the transition point, this being recorded as zero time. In a further series of experiments, C. curvata $\mathrm{D}$ was grown in a single stage as before. Sodium $\left[1-^{-14} \mathrm{C}\right]$ acetate $[1 \mathrm{ml} ; 125$

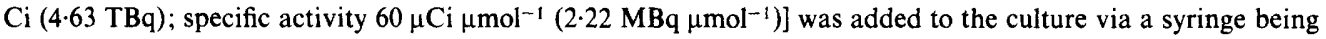
inserted into the medium itself. After $\mathbf{4 5}$ min equilibration, the incoming media was switched from nitrogenlimited to carbon-starvation. (The expelled air from the chemostat was passed through two Drechsel bottles containing $20 \%, \mathrm{w} / \mathrm{v}, \mathrm{KOH}$ in order to absorb any labelled $\mathrm{CO}_{2}$ before being led to the atmosphere.) Samples were periodically taken in duplicate from the chemostat for appropriate analyses.

Analyses. Dry weight. Samples $(10 \mathrm{ml})$ were centrifuged at $5000 \mathrm{~g}$ for $5 \mathrm{~min}$ in pre-weighed, dried tubes and washed twice with $10 \mathrm{ml}$ distilled water. The pellets were dried at $80^{\circ} \mathrm{C}$ over $\mathrm{P}_{2} \mathrm{O}_{5}$ in a vacuum oven until constant weight (about $48 \mathrm{~h}$ ).

Glucose. The concentration of glucose in medium samples was determined using the glucose-oxidase-peroxidase method (Boehringer).

Ammonia. The concentration of $\mathrm{NH}_{4}^{+}$in the medium samples was determined by the method of Chaney \& Marbach (1962).

Lipid. Total lipid was determined by a method based on that of Folch et al. (1957). Lipid was extracted from freeze-dried cells with chloroform/methanol $(2: 1, \mathrm{v} / \mathrm{v})$, filtered and washed with $0.9 \% \mathrm{NaCl}$ and then distilled water. The extract was dried over anhydrous $\mathrm{MgSO}_{4}$, and the solvent evaporated using a rotary vacuum evaporator. The lipid was redissolved in diethyl ether and transferred to a pre-weighed vial. The ether was removed in a stream of nitrogen and the residue dried in a vacuum desiccator for $1 \mathrm{~h}$.

Glycogen. Glycogen content of cells was determined by the method of Gunja-Smith et al. (1977). 
Determination of radioactivity. In lipid. Lipid was extracted as before and finally taken up in $1 \mathrm{ml}$ toluene. A sample $(100 \mu \mathrm{l})$ was transferred to $10 \mathrm{ml}$ scintillation fluid $(4 \mathrm{~g}$ PPO in 11 toluene) and counted.

In whole cells. A known volume of culture from the chemostat was centrifuged at $10000 \mathrm{~g}$ for $5 \mathrm{~min}$, washed once with water and resuspended in a minimum volume of water. The pellet was dried at $121^{\circ} \mathrm{C}$ over $\mathrm{P}_{2} \mathrm{O}_{5}$ in a vacuum oven until most of the water had evaporated. Soluene-100 (Packard) (1 ml) tissue solubilizer was added, and the vial was incubated at room temperature for $2 \mathrm{~h} ; 10 \mathrm{ml}$ of scintillation fluid $(4 \mathrm{~g}$ PPO, $60 \mathrm{~g}$ naphthalene, $20 \mathrm{ml}$ ethanediol, $100 \mathrm{ml}$ methanol and $880 \mathrm{ml}$ dioxan) was then added. The vials were stored in a dark cupboard overnight to reduce chemiluminescence and then counted.

In aqueous samples. Aqueous radioactive samples were counted by adding $1 \mathrm{ml}$ to $10 \mathrm{ml}$ of dioxan-based scintillation fluid (as above) held in a plastic vial. A standard to give counting efficiency and a blank to give background information were also counted for all determinations.

\section{RESULTS}

\section{Lipid utilization in starved oleaginous yeasts growing in batch culture}

The effect of transferring cells already having accumulated lipid in a nitrogen-limited growth medium to a carbon-starvation medium led to significant utilization of lipid in all but two cases (Table 1). With all yeasts except the two strains of Lipomyces starkeyi, the depletion of endogenous lipid was accompanied by an increase in cell biomass. Both strains of $L$. starkeyi failed to show any biomass increase during the $36 \mathrm{~h}$ of starvation and one strain (CBS 1809) only utilized its accumulated lipid very poorly with less than $20 \%$ of the available lipid being consumed. The other strain examined (CBS 2512) consumed less than $40 \%$ of its stored lipid.

Thus, three of the four species of yeast examined, C. curvata, Rhodosporidium toruloides and Trichosporon cutaneum, utilized the stored lipid with an accompanying increase in biomass. As the results with these three yeasts were not dissimilar, further studies were done with C. curvata D.

\section{Lipid utilization in two-stage continuous culture}

C. curvata $\mathrm{D}$, when grown in a two-stage chemostat with the first stage being nitrogen-limited and the second stage being a carbon-starvation environment, utilized its lipid reserves in proportion to the time that the cells were held in vessel 2 , i.e. the residence time (Table 2). In all cases, the final lipid content of the starved cells was $6 \%$ or less of the biomass which represented better than $80 \%$ utilization of the total lipid.

The calculations for the conversion of lipid into new biomass (Table 2) take into account that the original biomass entering vessel 2 consumes its own lipid and any increase in biomass which occurs is therefore effectively from the lipid-free biomass value. An additional factor has also been taken into account in these calculations which allows for some of the biomass increase to occur from the residual glucose being transferred from vessel 1 into vessel 2 . (It has been assumed that the $2 \mathrm{~g}$ glucose $1^{-1}$ entering vessel 2 would have yielded $1 \mathrm{~g}$ new cells $\mathrm{l}^{-1}$.)

The conversion of stored lipid into new biomass was, apart from the cells being held in vessel 2 with the longest residence time, remarkably constant at $2.6 \pm 0.2 \mathrm{~g}$ biomass per $\mathrm{g}$ lipid consumed. As this value exceeds the approximate theoretical value of about $1: 1 \cdot 7(\mathrm{w} / \mathrm{w})$ for the conversion of triacylglycerol to biomass, some of this biomass must have arisen from the yeast extract (at $1.5 \mathrm{~g} \mathrm{1}^{-1}$ ) in the incoming carbon-starvation medium. This, we assume, may have accounted for approximately $0 \cdot 7 \mathrm{~g}$ cells, thus leaving $1.9 \pm 0 \cdot 2 \mathrm{~g}$ cells which could only have been derived from the stored lipid being used in conjunction with the external $\mathrm{NH}_{4}^{+}$supply.

C. curvata $\mathrm{D}$ was subsequently found to accumulate, in addition to the lipid, about $10 \%(\mathrm{w} / \mathrm{w})$ of its biomass as glycogen. Upon starvation for $24 \mathrm{~h}$ in batch culture (see above) this decreased to about $3 \%(\mathrm{w} / \mathrm{w})$ and was thus evidently a second storage material for the cells. However, this glycogen could not have accounted for any of the biomass increase recorded in Table 2 as even optimal utilization of glycogen could only have yielded an equal weight of biomass (if, for example, it was converted to cell envelope polysaccharide) and would, if converted to other cell intermediates, lead to a net depletion of the biomass. The contribution of glycogen (positive or negative) has thus been ignored in our calculations. 
Table 1. Effect of carbon starvation on the biomass and lipid content of oleaginous yeasts in batch culture

Yeasts were grown for $5 \mathrm{~d}$ on nitrogen-limited media $(700 \mathrm{ml})$ in 11 vortex-aerated vessels at $30^{\circ} \mathrm{C}$ (stage 1 ). A volume of culture was then aseptically transferred to a similar vessel containing carbon-free medium $(400 \mathrm{ml})$ and growth allowed to continue for a further $36 \mathrm{~h}$ (stage 2). Experiments were done three times; the results are means of the three.

\begin{tabular}{|c|c|c|c|c|c|c|c|c|c|}
\hline & \multicolumn{3}{|c|}{ Stage 1} & \multicolumn{6}{|c|}{ Stage 2} \\
\hline & $\begin{array}{c}\text { Dry wt } \\
\left(\mathrm{g}^{-1}\right)\end{array}$ & $\begin{array}{c}\text { Lipid } \\
(\%, w / w)\end{array}$ & $\begin{array}{c}\text { Vol. of } \\
\text { medium } \\
\text { transferred } \\
\text { to stage } 2 \\
(\mathrm{ml})\end{array}$ & $\begin{array}{c}\text { Initial } \\
\text { glucose } \\
\text { concn } \\
\left(\mathrm{g} \mathrm{l}^{-1}\right)\end{array}$ & $\begin{array}{c}\text { Final } \\
\text { glucose } \\
\text { concn } \\
\left(\mathrm{g} \mathrm{l}^{-1}\right)\end{array}$ & $\begin{array}{c}\text { Dry wt } \\
\left(\mathrm{g} \mathrm{l}^{-1}\right)\end{array}$ & $\begin{array}{c}\text { Lipid } \\
(\%, \text { w/w })\end{array}$ & $\begin{array}{c}\text { Increase } \\
\text { in total } \\
\text { biomass } \\
\text { after } 36 \mathrm{~h} \\
\text { (g) }\end{array}$ & $\begin{array}{l}\text { Decrease } \\
\text { in total } \\
\text { lipid } \\
\text { after } 36 \mathrm{~h} \\
\text { (g) }\end{array}$ \\
\hline Candida curvata $\mathrm{D}$ & $9 \cdot 2$ & 34 & 240 & 0.6 & 0.025 & 4.48 & 8 & 0.67 & 1.29 \\
\hline Candida curvata $\mathrm{R}$ & $8 \cdot 2$ & 28 & 215 & 0.045 & 0.03 & $3 \cdot 28$ & 11 & $0 \cdot 25$ & 0.91 \\
\hline Lipomyces starkeyi CBS 2512 & $10 \cdot 8$ & 31 & 230 & $0 \cdot 054$ & 0.022 & 3.95 & 18.8 & 0.01 & $0 \cdot 31$ \\
\hline Rhodosporidium toruloides CBS 14 & $9 \cdot 1$ & 24 & 209 & 0.043 & 0.033 & $3 \cdot 86$ & $2 \cdot 8$ & 0.45 & $0 \cdot 39$ \\
\hline Rhodosporidium toruloides ML 2590 & $7 \cdot 5$ & 7 & 223 & $0 \cdot 47$ & 0.039 & $3 \cdot 14$ & $0 \cdot 4$ & 0.28 & $0 \cdot 11$ \\
\hline Rhodosporidium toruloides ATCC & & & & & & & & & \\
\hline 26217 & $9 \cdot 4$ & 22 & 201 & 0.25 & 0 & $3 \cdot 7$ & 1.7 & $0 \cdot 33$ & $0 \cdot 38$ \\
\hline Trichosporon cutaneum 40 & 11.9 & 23 & 233 & 0.27 & $0 \cdot 035$ & 4.91 & 5.9 & 0.33 & 0.46 \\
\hline
\end{tabular}


Table 2. Conversion of lipid to new biomass with C. curvata D growing in two-stage continuous culture with varying times of residence in vessel 2

Subscripts to columns $A, B$ and $C$ (e.g. $A_{1}$ ) indicate data from vessel 1 or vessel 2.

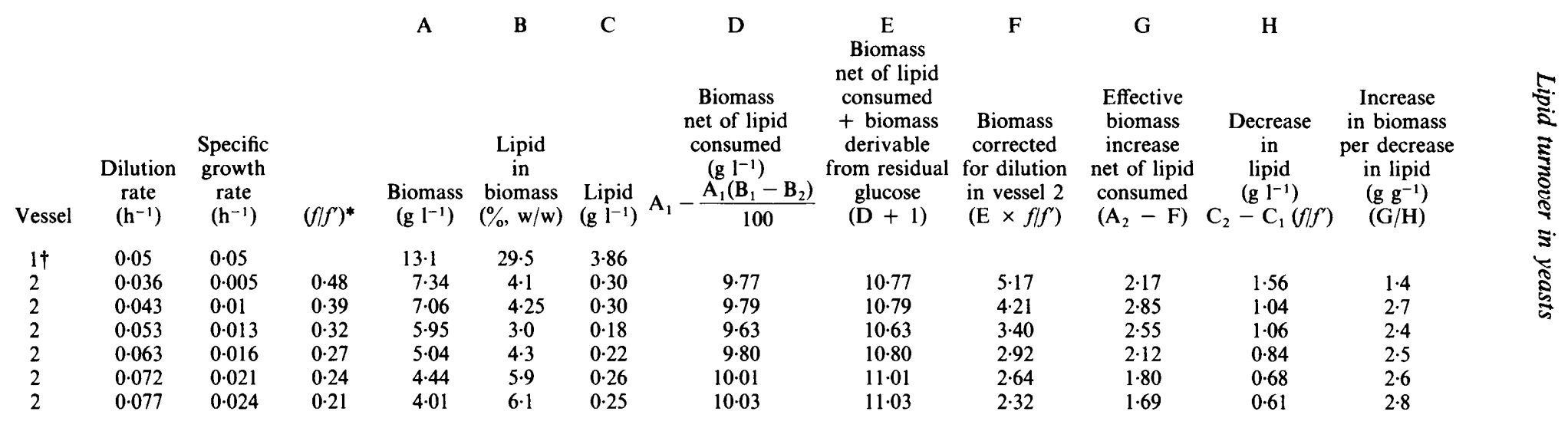

* Dilution factor, where $f$ and $f^{\prime}$ are the flow rates of culture entering and leaving vessel 2, respectively.

$\dagger$ Mean values pertaining in vessel 1 , acting as a feed vessel over course of run: biomass, $\pm 0.7 \mathrm{~g}^{-1}$; percentage lipid, $\pm 1 \cdot 5$, residual glucose, $2 \mathrm{~g}^{-1}$. 


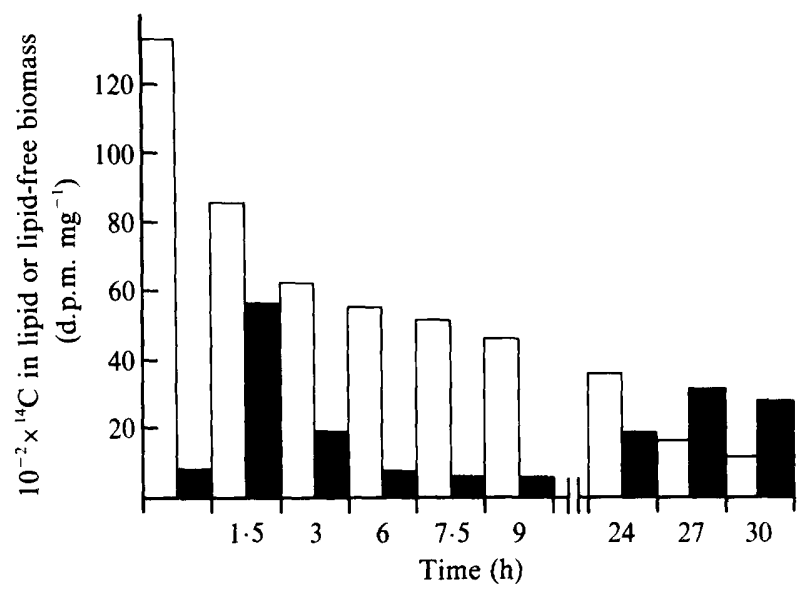

Fig. 1. Distribution of ${ }^{14} \mathrm{C}$, derived from $\left[{ }^{14} \mathrm{C}\right]$ acetate, between lipid and lipid-free biomass during transition of $C$. curvata $\mathrm{D}$ from nitrogen-limited medium to carbon-starvation medium in a single-stage chemostat. $\square$, d.p.m. per mg lipid; 1 , d.p.m. per mg lipid-free biomass. (This experiment was done in duplicate; the results are means of the two.)

To confirm that direct utilization of lipid into biomass was occurring further experiments were done using a transition, single-stage chemostat culture involving the use of ${ }^{14} \mathrm{C}$-labelled lipid.

\section{Lipid utilization in a single-state transition chemostat}

Use of $\left[{ }^{14}\right.$ C]acetate. A culture of $C$. curvata $\mathrm{D}$ growing in a single-stage chemostat under nitrogen-limited conditions was labelled with $\left[1-{ }^{14} \mathrm{C}\right]$ acetate (see Methods). Previous work (Botham \& Ratledge, 1979) had shown that, following injection of $\left[{ }^{14} \mathrm{C}\right]$ acetate into a chemostat culture of an oleaginous yeast growing under the same conditions, the label was readily incorporated into lipid and reached a steady-state distribution within $15 \mathrm{~min}$ with no subsequent turnover. Accordingly, with the culture of $C$. curvata, the medium was changed 45 min after the presentation of $\left[1-{ }^{14} \mathrm{C}\right]$ acetate to carbon-starvation medium. At this point, about $96 \%$ of the total radioactivity had become incorporated into the lipid, the remaining $4 \%$ was in the remainder of the cells and negligible ${ }^{14} \mathrm{C}$ remained in the medium.

Upon the onset of starvation, ${ }^{14} \mathrm{C}$ was lost from the lipid and after $1.5 \mathrm{~h}$ (the first time of sampling) $40 \%$ of the label in the lipid had been lost but was recovered in the cell biomass (Fig. 1). However from $1.5 \mathrm{~h}$ to $3.0 \mathrm{~h}$, the ${ }^{14} \mathrm{C}$ within the lipid declined less rapidly but a substantial part of the ${ }^{14} \mathrm{C}$ which had been incorporated into the biomass was now lost, presumably as ${ }^{14} \mathrm{CO}_{2}$. This loss is greater than the simple subtraction of the two consecutive values given in Fig. 1 as obviously ${ }^{14} \mathrm{C}$ in lipid would have continued to have been transferred into the remainder of the biomass during the intervening $1.5 \mathrm{~h}$. Evidently, the ${ }^{14} \mathrm{C}$ in the biomass was only partially incorporated into new cell material with the majority being in a readily metabolizable pool.

After $3 \mathrm{~h}$ of starvation, the rates of ${ }^{14} \mathrm{C}$ loss from the lipid and biomass were approximately that due to wash-out of the cells from the chemostat. However, towards the end of the starvation period $(24-30 \mathrm{~h}),{ }^{14} \mathrm{C}$ began to accumulate in the biomass indicating that a gradual movement was occurring in the relocation of the ${ }^{14} \mathrm{C}$ from its readily metabolizable pool into more permanent macromolecules.

Turnover in unlabelled cells. Using the same protocol as above, but omitting the presentation of $\left[{ }^{14} \mathrm{C}\right]$ acetate prior to initiating starvation, the changes in biomass and lipid content of C. curvata were followed over $36 \mathrm{~h}$ (Fig. $2 a$ ). The lipid content of the yeast fell rapidly over the first $4 \mathrm{~h}$, decreasing from 30 to $21 \%(\mathrm{w} / \mathrm{w})$ of the biomass; this was followed by a fairly steady drop from 

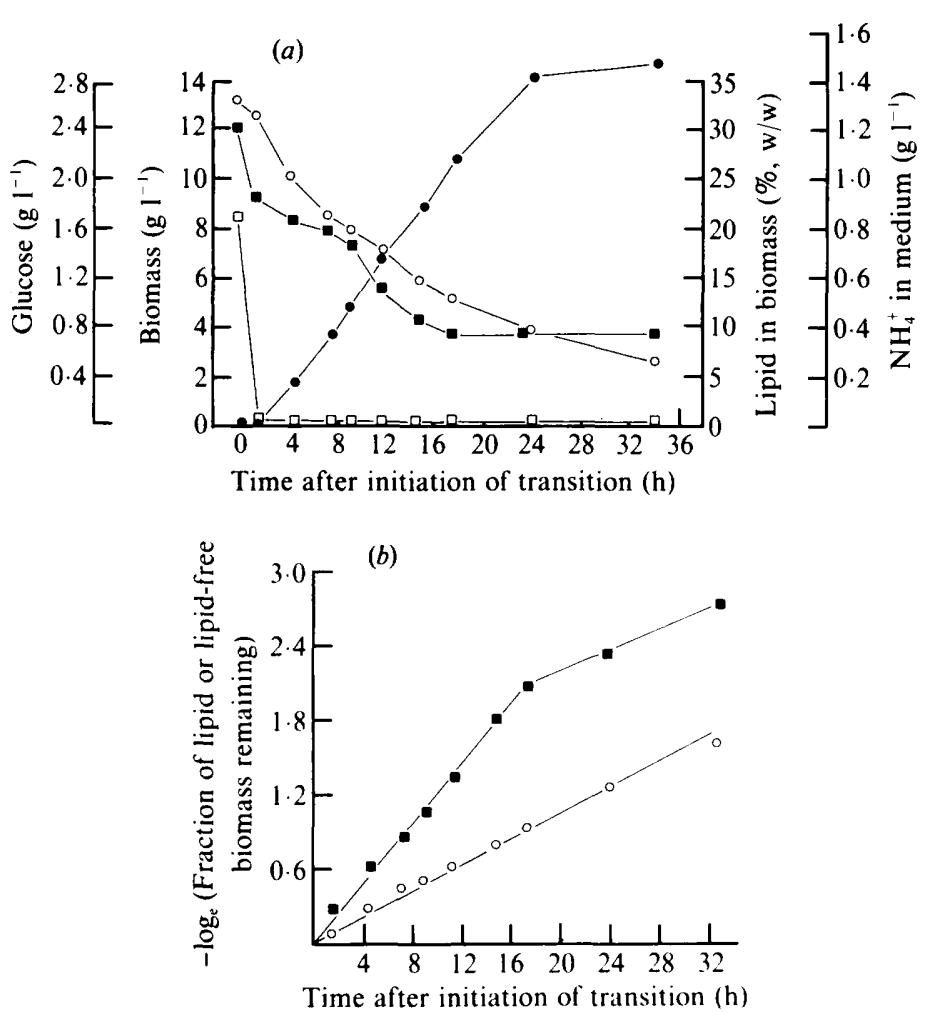

Fig. 2. Changes in the biomass and lipid content of $C$. curvata $\mathrm{D}$ growing in a chemostat at $D=0.05 \mathrm{~h}^{-1}$ following transition from nitrogen limitation to carbon starvation. $(a): \mathrm{NH}_{4}^{+}$in medium (O); biomass (O); lipid in cells ( $\square$ ); glucose in medium ( $\square$ ). (b) Exponential rates of loss of lipid ( $\square$ ) and biomass

(O). (The experiment was done in duplicate with concurring results; the data are for one experiment.)

21 to $10 \%(\mathrm{w} / \mathrm{w})$ over the next $12 \mathrm{~h}$. The lipid content then remained constant at about $10 \%$ $(\mathrm{w} / \mathrm{w})$. The biomass of the yeast fell slowly over the first $1.5 \mathrm{~h}$ compared with the decrease in lipid level. This was followed by a gradual decrease from 12.6 to $2.7 \mathrm{~g}^{-1}$ over the next $32 \mathrm{~h}$.

The glucose concentration in the medium fell immediately after the onset of starvation to reach a negligible value $\left(<0.1 \mathrm{~g} \mathrm{l}^{-1}\right)$ after $1.5 \mathrm{~h}$. The $\mathrm{NH}_{4}^{+}$concentration (which was initially zero) rose to reach a steady value of $1.5 \mathrm{~g} \mathrm{l}^{-1}$ after $24 \mathrm{~h}$.

As the wash-out of cells from the chemostat must be taken into consideration in calculating the rate of lipid turnover, the data of Fig. $2(a)$ were recalculated as a $\log _{\mathrm{e}}$ plot of the fraction of lipid (or biomass) remaining in the chemostat; i.e. $\log _{\mathrm{e}}\left(l_{\mathrm{t}} / l_{0}\right)\left[\right.$ or $\left.\log _{\mathrm{e}}\left(x_{\mathrm{t}} / x_{0}\right)\right]$ where $l_{\mathrm{t}}\left(\right.$ and $\left.x_{\mathrm{t}}\right)$ are the concentrations of lipid (or biomass) in the chemostat at time $t$, and $l_{0}$ (and $x_{0}$ ) are the initial values. This recalculation (Fig. $2 b$ ) showed that the rate of lipid loss was biphasic: from zero time up to $17 \mathrm{~h}$ the rate of loss corresponded to $0.12 \mathrm{~h}^{-1}$ and afterwards was $0.041 \mathrm{~h}^{-1}$ and approximately equal to the dilution rate of $0.05 \mathrm{~h}^{-1}$. The rate of loss of biomass was constant throughout the period of the experiment $\left(-0.048 \mathrm{~h}^{-1}\right)$.

\section{DISCUSSION}

Lipid may accumulate to over $70 \%$ of the biomass in several oleaginous yeasts and it has always been presumed that this is a storage material which confers some advantage to the cell should it subsequently enter a period of starvation. Although some yeasts do readily degrade their stored lipid, and use it to provide carbon for cell growth, not all do so rapidly; both strains of Lipomyces starkeyi showed only a poor ability to use their accumulated lipid. 
The other oleaginous yeasts examined, C. curvata, Rhodosporidium toruloides and Trichosporon cutaneum all readily used their lipid reserves upon starvation and could evidently produce some new biomass from the lipid. More extensive work with $C$. curvata using one- and two-stage chemostat cultures then confirmed that lipid could indeed be degraded to yield new biomass. The conversion of lipid to new biomass appeared to be high with our calculations indicating that up to $1.9 \mathrm{~g}$ new cells could be produced from $1 \mathrm{~g}$ lipid. It should though be appreciated that these starved cells did have $\mathrm{NH}_{4}^{+}$(and $\mathrm{O}_{2}$ ) available to them with which to synthesize new proteins, nucleic acids etc. When ${ }^{14} \mathrm{C}$-labelled lipid was created, the label was readily lost upon the cells being starved; the released ${ }^{14} \mathrm{C}$ appeared to go through a transitory, metabolizable pool perhaps intermediates of the tricarboxylic acid cycle - before eventual incorporation into the macromolecules of the cell. When the rate of lipid turnover was examined in a continuous culture undergoing transition from nitrogen-limitation (i.e. lipogenic conditions) to carbonstarvation, two pools of lipid could be discerned. Approximately $70 \%$ of the total lipid was lost at a steady but rapid rate (approximately 2.5 times faster than the growth rate) over the first $17 \mathrm{~h}$; this we presume corresponds to utilization of the triacylglycerols which constitute the bulk of the stored lipid (though this was not checked by lipid analysis). The remaining $30 \%$ of the lipid (= $9 \%$ of the cell biomass) which did not turn over would probably be structural lipid (i.e. mainly phospholipid, sterols and sterol esters). (In the two-stage chemostat experiments, the lipid decreased to between 4 and $6 \%$ in the starved cells with residence times of between 28 and $13 \mathrm{~h}$. The difference between the two results is attributed to differences in the protocols between the two experiments though it may be inferred that some of the so-called 'structural' lipid may be capable of degradation.)

Our results have shown that lipid degradation begins very rapidly after the onset of carbon exhaustion from the medium. Determinations done $1.5 \mathrm{~h}$ after initiation of starvation clearly showed that lipid had already begun to be consumed. One may presume this had commenced much earlier than this, possibly within a few minutes of loss of carbon from the medium. The factors which would trigger the appropriate intracellular lipases into such an immediate response are unknown but one is probably dealing with activation of the enzymes rather than waiting for enzyme induction.

Lipid degradation, besides being of importance in the physiology of the yeast cell, also is important when considering potential industrial processes for lipid production. Lipid breakdown could obviously be triggered during the processing of a yeast and lengthy periods without a metabolizable external carbon source must obviously be avoided as our results would suggest that breakdown of stored lipid is a readily instigated event.

This work was carried out with the aid of a SERC-CASE studentship to J.E.H. operated in conjunction with Cadbury-Schweppes; we thank Drs R. Moreton and R. Gibson for their sustained interest in this work.

\section{REFERENCES}

Botham, P. A. \& Ratledge, C. (1979). A biochemical explanation for lipid accumulation in Candida 107 and other oleaginous micro-organisms. Journal of General Microbiology 14, 361-375.

Chaney, A. L. \& Marbach, E. P. (1962). Modified reagents for the determination of urea and ammonia. Clinical Chemistry 8, 130-132.

DAWES, E. A. (1985). Starvation, survival and energy reserves. In Bacteria in their Natural Environments, pp. 43-79. Edited by $M$. Fletcher and G. D. Floodgate (Special Publication no. 16 of the Society for General Microbiology). London: Academic Press.

Dawes, E. A. \& Senior, P. J. (1973). The role and regulation of energy reserve polymers in microorganisms. Advances in Microbial Physiology 10, 135 266.

DEINEMA, M. H. (1961). Intra- and extra-cellular lipid production by yeasts. $\mathrm{PhD}$ thesis, Agricultural University, Wagingen, The Netherlands.
Folch, J., Lees, M. \& Sloan-Stanley, G. H. (1957). A simple method for the isolation and purification of total lipid from animal tissues. Journal of Biological Chemistry 226, 497-509.

Gunja-Smith, Z., Patil, N. B. \& Smith, E. E. (1977). Two pools of glycogen in Saccharomyces. Journal of Bacteriology 130, 818-828.

RATLEDGE, C. (1986). The potential of micro-organisms for oil production - a review of recent publications. In Proceedings of the World Conference on Emerging Technologies in the Fats and Oils Industry, pp. 318-330. Edited by A. R. Baldwin. Champaign, Illinois: American Oil Chemists' Society.

Ratledge, C. \& Boulton, C. A. (1985). Fats and Oils. In Comprehensive Biotechnology, vol. 3, pp. 983-1003. Edited by S. Drew, D. I. C. Wang \& H. Blanch. Oxford: Pergamon Press. 